\title{
Teatro de temática científica: conceituação, conflitos, papel pedagógico e contexto brasileiro
}

\section{Scientific theme theatre: definition, conflicts, educational roles and the Brazilian context}

Leonardo Maciel Moreira $^{1}$ • Martha Marandino ${ }^{2}$

\begin{abstract}
Resumo: O teatro de temática científica ainda é um fenômeno recente no Brasil. Ele se configura como um tipo de teatro que se propõe favorecer a divulgação e a educação científica. Apesar de não existirem muitas pesquisas acadêmicas sobre esse tema, o teatro de temática científica tem sido uma prática de professores da Educação Básica e Superior, bem como de instâncias não formais de educação. Este artigo tem como objetivo realizar uma análise sistematizada do teatro de temática científica, visando à educação em ciências. Para isso, será problematizado o termo teatro de temática científica, explicitando sua definição e sua articulação com alcance de uma alfabetização científica. Ao final, são enunciados grupos e projetos no Brasil que realizam esse tipo de atividade, focalizando suas produções e propostas.

Palavras-chave: Teatro científico. Educação em ciências. Divulgação científica. Popularização da ciência. Alfabetização científica.
\end{abstract}

\begin{abstract}
Scientific theatre is still a recent phenomenon in Brazil. It is configured as a type of theatre that encourages the dissemination of science and science education. Although there are not many academic researches on this topic, science theatre has been a practice of within basic and higher education, as well as non-formal education. This article has as its objective to carry out a systematic analysis of scientific theatre in science education. For this reason we examine the term scientific theatre, explaining its definition and its linkage with a scientific literacy. Finally, we list groups and projects in Brazil that perform this type of activity, focusing on their productions and proposals.
\end{abstract}

Keywords: Science theatre. Science education. Popularization of science. Scientific literacy.

\footnotetext{
${ }^{1}$ Universidade Federal do Rio de Janeiro (UFRJ), Rua Aloisio Gomes da Silva, 50, Laboratórios de Química, Granja dos Cavaleiros, CEP 27930560, Macaé, RJ, Brasil. E-mail: <leo.qt@hotmail.com>

${ }^{2}$ Departamento de Metodologia do Ensino e Educação Comparada, Faculdade de Educação, Universidade de São Paulo (USP), São Paulo, SP, Brasil.
} 
A educação em ciências, na perspectiva da alfabetização científica, exige um processo contínuo, ao longo de toda a vida, e difícil de se encerrar no universo da escola, da educação formal. A escola é a responsável por auxiliar os educandos na construção dos primeiros conceitos científicos, entretanto os currículos, os programas e os horários impedem o acompanhamento do rápido desenvolvimento científico. Dessa maneira, conquanto se constate a essencialidade da educação formal no processo de alfabetização científica, percebe-se que, isolada, ela não é suficiente. Por isso, a alfabetização científica torna-se dependente, também, da educação não formal, por meio da qual os sujeitos poderão complementar sua cultura científica.

Diversas atividades têm sido empregadas no sentido de dar continuidade à alfabetização científica dos cidadãos. Nesse sentido, alguns autores têm ressaltado a importância da linguagem teatral enquanto meio para divulgar e popularizar a ciência (MATEUS, 2005; MONTENEGRO et al., 2005). Assim, a apreciação da divulgação científica por intermédio do teatro torna-se importante na atualidade, uma vez que tanto instâncias não formais como museus e centros de ciências, quanto sujeitos atuantes na educação formal, tais como professores de ciências (da Educação Básica e do Ensino Superior), recorrem a essa estratégia. Também há que se considerar que a pesquisa na interface educação, ciência e teatro é indispensável para que essa temática seja discutida com fundamentação científica; e para que sejam produzidas orientações que auxiliem curadores, professores e pesquisadores interessados em desenvolver ações nesse âmbito. Este artigo tem como objetivo realizar uma análise sistematizada do teatro de temática científica visando à educação em ciências.

\section{A alfabetização científica e o teatro de temática científica}

A alfabetização científica (AC) tem sido tratada, pelos especialistas, pelo menos em três vertentes: conjunto de propósitos para uma reforma do ensino de ciências, metáfora para expressar as finalidades e objetivos da educação em ciências, e mito cultural - utopia a se seguir como promoção ao acesso à ciência (ACEVEDO DÍAZ; VÁZQUEZ ALONSO; MANASSERO MAS, 2003). Uma pessoa alfabetizada cientificamente deve: possuir conhecimentos das relações entre ciência e sociedade, da ética científica, da natureza da ciência, diferenciar ciência de tecnologia, possuir conhecimento sobre conceitos científicos básicos, e entender as relações entre as ciências e as humanidades, sendo que todo o processo de desenvolvimento da AC deve favorecer a liberdade intelectual dos sujeitos (PELLA; O'HEARN; GALE, 1966). Sasseron e Carvalho (2011) têm organizado essas proposições em três eixos: a compreensão básica de termos, conhecimentos e conceitos científicos fundamentais; a compreensão da natureza das ciências, e o entendimento das relações existentes entre ciência, tecnologia, sociedade e meio ambiente.

A AC propõe um conhecer ciência e tecnologia para além dos conteúdos conceituais tradicionalmente contemplados nos processos de ensino e aprendizagem. Esse processo se inicia na educação formal e tem continuidade na educação não formal, ao longo de toda a vida dos sujeitos. Quando se fala em natureza da ciência e da tecnologia, torna-se importante o conhecimento dos aspectos humanos, éticos e políticos que são constitutivos dessas práticas, bem como sobre os processos pelos quais os conhecimentos científicos e tecnológicos são produzidos. Tão importante, também, é o conhecimento a respeito da relação entre ciência, 
tecnologia, sociedade e meio ambiente, no sentido de se entenderem: relações de causa e efeito, custo e benefício, situações de risco, aspectos econômicos, dentre outros. A consequência dessa perspectiva seria a modificação da própria relação do sujeito com o conhecimento científico e tecnológico. A ciência e a tecnologia deixam de ser vistas como algo de utilidade somente prática, como ferramenta, e passariam a ser consideradas como parte da cultura. Ou seja, elas entrariam para o rol de hábitos, pensamentos, crenças e visão de mundo dos sujeitos.

O teatro de temática científica (também chamado de teatro científico) é uma atividade que vem ganhando vulto no cenário brasileiro, entre as ações que se propõem a discutir a ciência e a tecnologia para além dos aspectos conceituais (MOREIRA, 2013). O teatro de temática científica vem sendo chamado, pela literatura inglesa, de science theatre ou de museum theatre, dependendo do contexto onde se desenvolve. Para Saraiva (2007), o teatro de temática científica engloba espetáculos que ocorrem em museus e centros de ciências ou em escolas, com a preocupação de abordar os temas científicos numa vertente pedagógica. Os espetáculos abordam conceitos científicos, muitas vezes complexos e complicados, visando torná-los mais acessíveis, remetendo, posteriormente, a discussão para a sala de aula. Gunderson (2006) diferencia o teatro de temática científica em três tipos: (i) peças com cientistas famosos como personagens; (ii) peças cujos personagens são cientistas anônimos; e (iii) peças que utilizam a ciência como metáfora. Nessa classificação, nota-se um privilégio à figura do cientista, uma vez que duas categorias se preocupam em ressaltar o homem dentro de sua obra e somente uma delas se propõe a discutir a ciência, ainda assim enquanto metáfora. Essa classificação guarda dissonâncias com a proposta de Saraiva (2007), por caracterizar essa prática mais por ter inspiração no ser cientista, na ciência e no fazer científico do que na abordagem pedagógica de conceitos.

Barbacci $(2002,2004)$ sugere duas vertentes: o teatro usado como apoio didático para transmissão de conceitos científicos e a ciência emprestando seu conteúdo de ciência ao teatro. Dentro da primeira categoria surgem duas ramificações: (i) o teatro como técnica de apoio didático e o (ii) teatro derivado das conferências científicas. Da segunda categoria decorrem as perspectivas do (iii) teatro abordando questões éticas sobre a responsabilidade da ciência e dos cientistas, (iv) o teatro apontando uma reflexão existencial, (v) o teatro encenando biografias ou episódios da história da ciência, e (vi) o teatro usando a ciência (neurobiologia, antropologia, anatomia etc.) como apoio para a criação artística. Quando das possibilidades (i) e (ii), os elementos do teatro (luzes, som, vocabulário dramático etc.) ajudam na aproximação entre público leigo e universo da ciência, devido à sua principal força, a comunicação emotiva e sensória. Assim, atividade pedagógica e entretenimento assumem o objetivo principal de despertar a curiosidade sobre o mundo da ciência.

A perspectiva acima mencionada é frequente em museus, instituições científicas e shows de ciências. Nas ramificações iii, iv, v e vi, a criação dramática é inspirada pela ciência sem qualquer propósito específico de comunicação de conteúdos, e continua mantendo suas características artísticas e estéticas, objetivando incrementar a imaginação científica do público. Nessa perspectiva, o teatro evidencia aspectos da ciência como elementos para uma reflexão existencial, levando o homem a questionamentos profundos a respeito do sentido da existência no mundo e da responsabilidade pelos seus feitos, gerando questões sobre o sentido da história, da vida e da morte.

Apesar de a proposta de Barbacci $(2002,2004)$ ser mais abrangente, percebe-se, em seu interior, a persistência da dissonância que sinalizamos entre Saraiva (2007) e Gunderson 
(2006), qual seja, a tensão entre a perspectiva de um teatro educativo (ou pedagógico), com foco na aprendizagem de conceitos científicos, e um teatro arte, com o foco no teatro enquanto obra de arte, e a ciência como mais outro assunto que ele pode abordar. O que estaria em jogo entre essas duas perspectivas? O teatro de temática científica deixa de ser arte por assumir um caráter mais pedagógico?

Bião (2009) discute sobre a relação da arte com outros campos. Para esse autor, a arte, entendida como fenômeno revelador e constitutivo da vida e do ser humano, constrói realidades e sentidos, cujas dimensões não se limitam às proposições (ou intenções) de outros construtos, tais como: a ciência, a educação, a política, dentre outros. Contudo, momentaneamente, ela pode submeter-se a quaisquer desses construtos, reduzindo temporariamente suas dimensões artísticas às dimensões do imaginário e do simbólico dos discursos da ciência, da educação, da política etc., sem diluir-se completamente. O que é caracteristicamente artístico persiste, ou seja, a arte pode se servir de todos os paradigmas simbólicos e imaginários, sem se submeter a nenhum deles. Nessa perspectiva o teatro de temática científica continua sendo arte.

Assim, qualquer que seja o assunto ou temática presente em uma peça de teatro, este estará em constante relação com a dimensão artística. Por isso, a ideia de subjugação não é adequada, ao ser simplista. O que ocorre é a diminuição da dimensão artística (resultante da pesquisa artística), que envolve estudos, experimentos e técnicas referentes ao trabalho de: corpo, voz, construção de personagens, interpretação, encenação, produção de texto, construção de cenários e figurinos etc. Nessa perspectiva, é um equívoco pensar em ausência de arte nas encenações que se propõem a discutir temáticas científicas. A questão, na verdade, é a maneira como a dimensão artística está presente nessas encenações. Nessa ótica, caberiam questões referentes a quanto estas encenações situam-se mais próximas de um teatro amador ou de um teatro profissional, admitindo-se, como critério para diferenciar essas duas práticas, a quantidade/qualidade da pesquisa artística, a dimensão artística.

O teatro de temática científica não possui um significado único, podendo variar desde uma abordagem mais conceitual a práticas artísticas que procuram inspiração na ciência e suas problemáticas. A proficuidade dessa prática reside na possibilidade de se conhecerem ciência e tecnologia para além dos seus conceitos, experimentos ou produtos, focalizando uma abordagem mais humanista. Assim, cientistas podem ser desnudados em seres humanos, com suas emoções e conflitos, e os experimentos poderiam ser contextualizados, conhecendo-se os interferentes sociais que influenciaram nas grandes descobertas científicas. Nessa mesma perspectiva, pode-se problematizar o papel do cientista na sociedade, e sua imagem, bem como questões a respeito do sentido da vida e do mundo, e os dilemas éticos, políticos, religiosos e históricos relacionados à ciência e à tecnologia.

Esse tipo de espetáculo teatral, que se destina a discutir a ciência, encontra denominação em práticas teatrais tais como: o teatro de tese e o teatro didático. De acordo com Pavis (2008, p. 385), o teatro de tese:

[...] é uma forma sistemática de teatro didático. As peças desenvolvem uma tese filosófica, política ou moral, buscando convencer o público de sua legitimidade convidando-o a analisar mais a reflexão que suas emoções. Toda peça apresenta, necessariamente, numa embalagem mais ou menos discreta, uma tese: a liberdade ou a servidão do homem, os 
perigos da avareza, a força do destino ou das paixões. O teatro de tese não hesita, no entanto, em formular os problemas num comentário bastante didático. [...] alguns dramaturgos escreveram peças que queriam fazer o público refletir, ou até mesmo obrigá-lo a mudar a sociedade.

Nessa prática de teatro, é desenvolvida a denominada peça de tese, que:

[...] expõe, através da cena, questões morais ou políticas sentidas como atuais. A dialética das personagens e de seus pontos de vista oferece o instrumento ideal para encarar ideias controvertidas. Nada obriga o autor a nomear um porta voz de sua posição pessoal, nem mesmo uma personagem próxima dele. Na maior parte do tempo, a fábula e o peso relativo dos carateres informam a respeito da possível solução do problema exposto. (PAVIS, 2008, p. 282)

$\mathrm{Na}$ análise dessas definições, se percebem identificações com o teatro de temática científica discutidas anteriormente. A título de ilustração, podemos considerar o espetáculo Oxigênio (DJERASSI; HOFFMAN, 2004), que trata de uma estória fictícia abordando bastidores históricos verídicos a respeito da descoberta do gás oxigênio, realizada, quase simultaneamente, pelo químico francês Lavoisier, pelo farmacêutico sueco Scheele e pelo pastor inglês Priestley. A questão principal da peça é a escolha de quem deverá ser o ganhador de um Prêmio Nobel retroativo.

A partir desse conflito, os autores desenvolvem uma tese filosófica a respeito do que seria uma descoberta científica e da postura dos cientistas frente à ciência e à humanidade. Durante toda a trama, os aspectos políticos e morais que permeiam a dinâmica acadêmica e as escolhas em ciências têm, nas personagens, sua porta-voz. Por meio do enredo, questões morais e políticas a respeito do fazer ciências, válidas à época e aplicáveis aos dias atuais, são problematizadas. A peça de Djerassi e Hoffman (2004), assim como outras mencionadas nesta pesquisa, provocam a reflexão e instruem o público acerca de assuntos referentes à ciência e, por isso, se identificam com a ideia de teatro didático.

É didático todo teatro que visa instruir seu público, convidando-o a refletir sobre um problema, a entender uma situação ou a adotar uma certa atitude moral ou política. Na medida em que o teatro geralmente não apresenta uma ação gratuita e privada de sentido, um elemento de didatismo acompanha necessariamente todo trabalho teatral. O que varia é a clareza e a força da mensagem, o desejo de mudar o público e de subordinar a arte a um desígnio ético ou ideológico. (PAVIS, 2008, p. 386)

A proposição do teatro de temática científica não é outra senão fazer o público refletir e estimular mudanças de comportamentos, funcionando como uma peça didática, a qual pressupõe que o público extraia dela ensinamentos para sua vida privada e pública. Nesse contexto, é possível encontrar uma filiação ideológica do teatro com temática científica no próprio campo das artes cênicas. No que se refere à proposição educativa, ao foco sobre a reflexão, e, por que 
não dizer, ao estímulo à liberdade intelectual, o teatro científico ressoa pensamentos e proposições da peça didática de Bertold Brecht.

De acordo com Koudela (1991), o contexto que permitiu a Brecht propor e escrever suas peças didáticas foi a luta de classes aguçada e a própria consciência de classe. A peça didática foi criada no intuito de interferir na organização social do trabalho, e pode ser considerada uma síntese entre tendências que procuraram articular teatro e pedagogia. Ela fundamenta-se na ideia de que o atuante possa ser influenciado socialmente pelo próprio processo de construção do espetáculo e dos personagens, assumindo para si determinadas formas de agir e de posturas, bem como reproduzindo falas. A imitação de modelos sociais e a crítica a esses modelos, por meio das diferentes possibilidades de atuação experimentadas, têm um papel importante. No processo da peça didática, a imitação não se traduz como uma maneira passiva de retratar a sociedade, mas, sim, como um processo em que, pela percepção e crítica da sociedade e de seus integrantes, chega-se a uma proposta de atuação. A intenção não é a de fixar ideias no atuante, mas, sim, de modificar o próprio método de pensar.

A peça didática ensina no momento mesmo em que nela se atua. Dessa maneira, o embrião da mudança social seria lançado somente entre os participantes do espetáculo. Conquanto o foco seja mesmo os atuantes, Brecht intenciona atingir a base das instituições formadoras de ideologia; assim, as apresentações públicas das peças didáticas, quando ocorriam, adquiriam função política ao demonstrarem e tornarem visíveis as contradições imanentes à sociedade, sempre com a proposição de provocarem as instituições e explicitarem suas estruturas (KOUDELA, 1991). Dessa maneira, pode-se entender que, mesmo para os espectadores, a peça didática constitui um estímulo à liberdade intelectual, ao pensamento crítico. Por isso, podem ser consideradas um método de intervenção no pensamento e de ação no plano social, gerando crítica e comportamento político, utilizando-se, para isso, da exploração da relação dialética entre teoria e prática, de maneira a expor as formas contraditórias da estrutura social vigente. No intuito de explicitar a prática da peça didática, Steingweg (1991) explica que o processo abrange a utilização de jogos teatrais que partem do texto para aprofundar as experiências e os conceitos sobre o mundo e a sociedade. Este mesmo autor propõe alguns itens visando manter o princípio da peça didática.

O teatro científico aproxima-se da ideia de peça didática de Brecht no que se propõe à intencionalidade educativa/pedagógica, focalizando assuntos relacionados à ciência e a tecnologia. Entretanto, se diferenciam quanto à estrutura, uma vez que a primeira tem como foco principal o espectador (a plateia), enquanto a outra o tem nos atuantes. Contudo, há que se considerar a proficuidade de um teatro científico que se fundamentasse nas proposições da peça didática. Esse teatro levaria para a cena as reflexões amadurecidas criticamente pelos atuantes, utilizando-se dos recursos lúdicos para comunicar, mas com foco na reflexão. O objetivo seria o de comunicar, mas sem nublar a percepção do espectador, colocando, em evidência, o estranhamento do que é socialmente comum no que tange à ciência e a tecnologia.

\section{Experiências de teatro de temática científica no Brasil}

O teatro de temática científica mostra-se como um potencial contribuidor para a alfabetização científica, em especial, no que se refere ao conhecimento da natureza da ciência e da 
tecnologia e das relações entre ciência, tecnologia, sociedade e meio ambiente. Essa proficuidade é perceptível tanto pelas discussões encontradas em pesquisas científicas quanto pela análise de grupos de teatro que se propõem a realizar essa prática.

Em estudo realizado sobre o texto Copenhagem, Silveira, Silva e Ribeiro Filho (2009) o consideram um material rico em termos de exploração de aspectos sociais e dos dilemas éticos na ciência, em especial, sobre os dois dos principais cientistas envolvidos na teoria quântica, Niels Bohr e Werner Heisenberg. As falas dos personagens, abordando os princípios de complementaridade e incerteza, favoreceriam o caráter de divulgação científica, auxiliando, também, na compreensão de conceitos da física. Moreira (2012) demonstra a potencialidade do teatro com temática científica para as discussões acerca da história e da filosofia da ciência, quando analisa a construção do conceito de cientista, focalizando as temáticas de poder e ambição, no texto teatral Oxigênio.

Pesquisadores da área da divulgação científica entendem a arte com temática científica como evolução das formas de se divulgar a ciência (ABREU, 2001; MASSARANI, 2004). A interação entre a ciência e a arte ofereceria maneiras diferenciadas de se representar o mundo (LOPES, 2005; MASSARANI; ALMEIDA, 2006; MATOS, 2003). Essa nova possibilidade traz consigo a perspectiva adicional de se abordar o aspecto emocional, já que os textos científicos não incluem a emoção da descoberta. Nesse sentido, Gardair e Schall (2009) ressaltam que o teatro, assim como a ciência, nos fornece um modo de ver o mundo, sendo que, para isto, esse último preocupa-se em mobilizar as emoções do espectador.

O teatro proporciona o conhecimento sobre ciência, contribuindo para uma maior aproximação da população ao conhecimento construído pela ciência e pela tecnologia, por propiciar a perspectiva de se abordar o aspecto humano da ciência. O teatro, enquanto arte, se propõe a discutir a vida, o homem, a existência. Quando a temática do espetáculo é científica, as discussões passam a abordar as dimensões vida, homem e existência na relação com a ciência e a tecnologia. Isso implica trazer para a cena: as relações humanas, os conflitos, os aspectos éticos, políticos e sociais,

Essa abordagem é que se verifica em núcleos brasileiros que exploram a interface entre teatro e ciências da natureza. Por exemplo, no estado do Rio de Janeiro, encontra-se o projeto Ciência em Cena, no Museu da Vida (Fundação Oswaldo Cruz, RJ), que tem, como objetivo, a pesquisa sobre ciência e arte e o desenvolvimento de atividades artísticas que promovam a apresentação e discussão de temas da ciência (LOPES, 2005). Alguns dos espetáculos realizados nesse projeto são: O mensageiro das estrelas, de Ronaldo Nogueira da Gama; Lição de botânica, de Machado de Assis e direção de Gustavo Ottoni; O mistério do barbeiro, direção de Jacyan Castilho; e Pergunte a Wallace, escrita por Geinor Styles, adaptada por Gustavo Ottoni e Wanda Hamilton. Nesses espetáculos, são abordadas as vidas de cientistas, como Galileu Galilei, Carlos Chagas e Alfred Russel Wallace, discutindo-se sobre o impacto e as implicações das pesquisas científicas sobre a sociedade e sobre os rumos da ciência. Também são abordados: o cientista enquanto sujeito questionador, conflitos entre sentimentos e carreira científica, o ser cientista e o fazer ciência, debate sobre questões éticas em torno da pesquisa com seres humanos. Os assuntos abordados por esse projeto dialogam diretamente com a necessidade de se conhecer sobre a natureza da ciência e tecnologia. Essa mesma proposição é encontrada no Palco da Ciência, da Casa da Ciência (RJ), que conta com 12 peças (SOARES, 2003), entre as quais estão: Em busca da estrela, texto de Larissa Câmara e direção de Chayanna Ferreira; Um voo para Santos Dumont, 
texto e direção de André Brilhante; Dumont - O sonho de um voador, texto de Mauro Barros e direção de Marcia Fernandes e Mauro Barros; Dançando no céu, texto de Stela Guedes Caputo e direção de Max Pereira Roca; O picadeiro em busca do tempo perdido, texto de André Brilhante e direção de Renato Carrera; e Einstein, texto de Gabriel Emanuel e direção de Sylvio Zilber ${ }^{3}$. E o projeto Ciênica, no Núcleo Arte, Mídia e Educação, da Universidade Federal do Rio de Janeiro, campus Macaé, com os espetáculos Esse rio é nosso! e Tabela periódica: a invenção. Esse projeto objetiva pesquisar o teatro com temática científica e auxiliar na enculturação artística e científica da população do norte fluminense.

No Ceará, encontra-se o Seara da Ciência, um espaço de divulgação científica e tecnológica da Universidade Federal do Ceará, que procura estimular a curiosidade pela ciência, cultura e tecnologia, mostrando suas relações com o cotidiano e promovendo a interdisciplinaridade entre as diversas áreas do conhecimento. Os textos têm como objetivo veicular conceitos científicos de forma simples, lúdica e agradável, na forma de diálogos bem humorados, motes para posteriores debates em sala de aula. Algumas das peças apresentadas são: Eu odeio insetos e Caixinhas da vida, de Betânia Montenegro e Ricardo Tannus, e Digestão: comida, calor e peso, de Betânia Montenegro. Contam, ainda, com a adaptação do texto Tem um cabelo na minha terra, de Gary Larson, na qual é abordado o tema equilíbrio ecológico. A trajetória e as contribuições de cientistas, como o físico, matemático e filósofo alemão Albert Einstein, o químico francês Antoine Laurent Lavoisier e o naturalista inglês Charles Darwin, também foram adaptadas em monólogos e encenadas por esse grupo. Uma importante obra do grupo foi Bioquímica em cena, de Marcus R. Vale, uma peça que tem como objetivo abordar as relações metabólicas mantidas entre vários sistemas do organismo humano (MONTENEGRO et al., 2005). No trabalho desenvolvido pelo Seara da Ciência, percebe-se a preocupação em privilegiar, também, a apresentação de conceitos científicos, favorecendo a compreensão de termos, conhecimentos e conceitos científicos fundamentais. Em Pernambuco, encontramos o Laboratorium Cênico, que tem, nos recursos do teatro, um meio de vivenciar novas estratégias de comunicação e interação com o público. Dentre os espetáculos já encenados, estão: Mateus e Catirina em o calor tá de rachar, onde personagens da cultura local explicam o que é aquecimento global; o Desadmirável Mundo Novo, retrata história do despertar de um cidadão comum que, depois de um pesadelo com um futuro de caos, decide fazer a diferença por meio da mudança em pequenos hábitos; e Show da Ciência: Tudo numa Folha de Papel, no qual vários experimentos são realizados com a participação do público ${ }^{4}$. Neste projeto, a abordagem da temática científica tende a desenvolver, com o público, noções com respeito à relação entre ciência, tecnologia, sociedade e meio ambiente.

Já no estado de São Paulo, encontra o núcleo Arte e Ciência no Palco, com um repertório de 12 espetáculos em mais dez anos de atuação, dentre eles, estão os premiados: Einstein (Prêmio Mambembe / FUNARTE em 1998), Da Vinci pintando o sete (Prêmio Maria Clara Machado), Copenhagem (Prêmio Qualidade Brasil e Prêmio Shell, em 2001), Quebrando Códigos (Prêmio Shell, em 2004), 20.000 léguas submarinas (Prêmio FEMSA, em 2004), e Perdida, uma

\footnotetext{
${ }^{3}$ Disponível em: < http://www.casadaciencia.ufrj.br/>. Acesso em: 12 out. 2013.

${ }^{4}$ Disponível em: <www.ufpe.br>. Acesso em: 12 out. 2013.
} 
comédia quântica, After Danwin, A dança do universo, Rebimboca \& Parafuseta e $A$ culpa é da ciência??. $\mathrm{O}$ Ouroboros, da Universidade Federal de São Carlos, com os espetáculos Além da Lenda, Magia $x$ Ciência, O quimico e o monstro, $O$ castelo bem assombrado, A caverna de Morgana, Lição de botânica $\mathrm{e}$ Estava escrito nas estrelas, dentre outros ${ }^{6}$. E o Núcleo de Artes Cênicas da Estação Ciência com a Cia. Fábula da Fíbula. Essa companhia realizou suas atividades no período de 1999 a 2013. Dentre suas ações destacam-se os espetáculos: A estrela da manhãa, texto de Calixto de Inhamuns e direção de Gabriela Rabelo; Conexões Cósmicas, direção de Wilton Amorin; Prof. Gervásio e a Energia Elétrica, texto de Cauê Mattos e Regina Arruda e direção de Regina Arruda; O monocórdio de Pitágoras, texto de Pedro Paulo Salles e direção de Cauê Mattos; O poeta e o vento, texto de Calixto de Inhamuns e direção de Gabriela Rabelo; e Larguem tudo! Vamos voar!, texto e direção de Darci Figueiredo. Nesses espetáculos, por diversas vezes, problematiza-se o cientista, a prática científica e suas consequências éticas, sociais e econômicas. O espetáculo Prof. Gervásio e a energia elétrica diferencia-se dos demais por ser caracterizado, pela Cia. Fábula da Fíbula, como uma aula-espetáculo. Esse formato é caracterizado por privilegiar a abordagem dos conceitos científicos e tecnológicos, focalizando a aprendizagem conceitual e favorecendo a compreensão básica de termos, conhecimentos e conceitos científicos fundamentais.

Ao discutirem sobre o trabalho realizado por algumas das companhias supracitadas, Montenegro et al. (2005) reforçam a importância da linguagem teatral, enquanto meio para divulgar e popularizar a ciência. Nesse sentido, Mateus (2005) relata que a montagem e apresentação do espetáculo Frankenstein: a ciência no divã tem possibilitado, a estudantes de graduação e de pós-graduação, que compõem o elenco, o desenvolvimento de habilidades de comunicação e conhecimento do processo de transposição didática; e, aos espectadores, o contato com informações sobre ciências de maneira mais prazerosa do que a rotina de sala de aula. Também Lupetti et al. (2007a, 2007b), considerando os resultados obtidos com questionários respondidos por espectadores de peças teatrais focalizando a Ciência, têm relatado que o teatro, enquanto atividade suplementar às desenvolvidas em sala de aula, é uma importante ferramenta para a divulgação e ensino de ciências, uma vez que desperta o interesse de crianças e jovens para vida cultural e científica.

\section{Considerações finais}

Nessa pesquisa, foi explicitado que o teatro de temática científica, por seus objetivos e práticas, contempla as perspectivas da alfabetização científica. $\mathrm{Na}$ análise realizada, verificase a abordagem da ciência e da tecnologia focalizando problemáticas que constituem o bojo das discussões sobre a alfabetização científica. Isso é um indício de como essa atividade pode auxiliar no conhecimento da ciência e da tecnologia

No teatro científico, há preocupação artística e com a informação científica; assim, a liberdade poética termina por ser limitada pela necessidade de clareza e precisão da comunicação

\footnotetext{
${ }^{5}$ Disponível em: <www.arteciencianopalco.com.br>. Acesso em: 12 out. 2013.

${ }^{6}$ Disponível em: < http://www.ufscar.br/ouroboros>. Acesso em: 12 out. 2013.
} 
da informação científica. Os espetáculos não poderiam se furtar de comunicar as concepções, as perspectivas e as informações academicamente aceitas. Para isso, é necessário o estabelecimento de uma parceria e comprometimento do artista com a ciência. Essa dinâmica diferenciada é uma característica do fenômeno teatro de temática científica. Entretanto, a liberdade poética se mantém presente tanto na maneira como a informação científica será comunicada, isto é, o teatro pode acontecer em diferentes possibilidades de encenação que o artista pode optar para a comunicação da informação científica; quanto nos questionamentos e proposições possíveis a partir dessa informação, que passam pelo estranhamento do cotidiano e pelas novas visões de mundo que o artista pode construir (ou estimular a plateia a construir).

Neste artigo, temos nos posicionado em favor do termo teatro de temática científica, em detrimento do termo teatro científico. Essa escolha deve-se à necessária explicitação de um aspecto do termo teatro científico que tem sido negligenciado pela literatura, ao menos pelos autores a que recorremos nessa pesquisa. $\mathrm{O}$ termo teatro científico pode carregar consigo a conotação de que somente nesse teatro há ciência, o que tem significado as ciências da natureza. Isso pode ser constatado pelos espetáculos apresentados, pela literatura, para o que seria o teatro científico. Essa denominação tende a ignorar o próprio teatro enquanto campo de produção de conhecimento e a desconsiderar a pesquisa no campo do teatro, que vêm crescendo e procurando se legitimar. Desde 1998, com a criação da Associação Brasileira de Pesquisa e Pós-Graduação em Artes Cênicas e com o apoio do Conselho Nacional de Desenvolvimento Científico e Tecnológico (CNPq), se tem constatado um aumento das pesquisas e dos programas brasileiros de pós-graduação em artes cênicas, resultante de representação da área em agências de coordenação e de financiamento, de reuniões científicas e artísticas periódicas e da divulgação das pesquisas. O impacto dessa nova organização pode ser percebido, por exemplo, pelo aumento no número de teses e dissertações registradas na Coordenação de Aperfeiçoamento de Pessoal de Nível Superior (CAPES), que, no quinquênio de 2000-2005, saltou de 121 para $220^{7}$. Outro aspecto a ser considerado é que, atualmente, existem espetáculos teatrais que são o resultado de experimentos de corpo, de voz, de encenação, entre outros, ou seja, configuram-se como resultado de procedimentos metodológicos envolvendo revisões bibliográficas, experimentações, sistematização de dados e produção de novos conhecimentos sem sequer tocar no universo das ciências da natureza. A rigor, esse último seria o teatro científico. Com o termo teatro de temática científica, designamos as propostas teatrais que, na encenação, abordam tanto as ciências da natureza quanto as ciências humanas, entre outras, seja como conteúdo conceitual, histórico, filosófico, cultural ou epistemológico, seja como inspiração artística.

O teatro de temática científica tem se apresentado como uma estratégia profícua para a alfabetização científica. Os recursos de iluminação, sonoplastia, cenografia, figurinos, performance dos atores (voz, corpo etc.), maquiagens, máscaras, objetos de cena, dentre outros, mobilizam a atenção do público e favorecem uma maior significação da ciência e da tecnologia. Ao final do espetáculo, para além do que é fornecido pelo texto teatral, o espectador leva consigo todas as impressões resultantes da encenação. Essas impressões constituem referências

\footnotetext{
${ }^{7}$ Dados retirados do banco de teses da CAPES. Disponível em: <http://capesdw.capes.gov.br/capesdw $>$. Acesso em: 05 fev. 2015. 
para que o sujeito compreenda e acesse os conhecimentos sobre ciência e tecnologia veiculados no espetáculo. Como ação complementar, em diversos desses espetáculos, ao final, abre-se um debate com o público, buscando esclarecer dúvidas e fazer comentários e sugestões.

Por fim, cabe ressaltar que a articulação entre teatro e ciências da natureza no Brasil, visando à divulgação científica, é ainda recente, e, por isso, apresenta diversos aspectos que precisam ser melhor estudados. Por exemplo, problemáticas resultantes: da formação da equipe que realiza essa prática, da tensão entre ciência e liberdade poética, da apreensão de conhecimentos científicos e tecnológicos, do impacto dessas práticas, dentre outros. O fomento à pesquisa na interface teatro e ciência é indispensável para que essa temática seja discutida com fundamentação científica, para que se tenha uma maior difusão em revistas de pesquisa, e para que sejam produzidas perspectivas que auxiliem curadores, professores e pesquisadores interessados em desenvolver projetos nesse âmbito.

\section{Referências}

ABREU, A. R. P. Estratégias de desenvolvimento científico e tecnológico e a difusão da ciência no Brasil. In: CRESTANA, S. (Org.). Educação para a ciência: curso para treinamento em centros e museus de ciência. São Paulo: Livraria da Física, 2001. p. 23-28.

ACEVEDO DÍAZ, J. A.; VÁZQUEZ ALONSO, A.; MANASSERO MAS, M. A. Papel de la educación CTS en una alfabetización científica y tecnológica para todas las personas.

Revista Electrónica de Enseñanza de las Ciencias, Vigo, v. 2, n. 2, p. 80-111, 2003. Disponível em: < http://reec.uvigo.es/volumenes/volumen2/REEC_2_2_1.pdf >. Acesso em: 04 fev. 2015.

BARBACCI, S. From the Golem to artificial intelligence: science in the theatre for an existential reflection. Journal of Science Communication, Trieste, v. 1, n. 3, p. 87-96, 2002.

. Science and theatre: a multifaceted relationship between pedagogical purpose and artistic expression. In: INTERNATIONAL CONFERENCE ON PUBLIC COMMUNICATION OF SCIENCE AND TECHNOLOGY, 8., 2004, Barcelona. Proceedings... Disponível em: < http://www.pantaneto.co.uk/issue19/barbacci.htm>. Acesso em: 12 out. 2013.

BIÃO, A. J. C. Etnocenologia e a cena baiana: textos reunidos. Salvador: P\&A Gráfica e Editora, 2009. Disponível em: < http:/ /www.teatro.ufba.br/gipe/arquivos_pdf/ ETNOCENOLOGIA1.pdf>. Acesso em: 04 fev. 2015.

DJERASSI, K.; HOFFMAN, R. Oxigênio. Rio de Janeiro: Vieira \& Lent, 2004.

GARDAIR, T. L. C.; SCHALL, V. T. Ciências possíveis em Machado de Assis: teatro e ciência na educação científica. Ciência \& Educação, Bauru, v. 15, n. 3, p. 695-712, 2009. Disponível em: < http://dx.doi.org/10.1590/S1516-73132009000300015>. Acesso em: 04 fev. 2015. 
GUNDERSON, L. Science plays come of age. The Scientist, Midland, 28 Jul. 2006.

Disponível em: <http://www.the-scientist.com/news/display/24160/>. Acesso em: 12 out. 2013.

KOUDELA, I. D. Brecht: um jogo de aprendizagem. São Paulo: Perspectiva, 1991.

LOPES, T. Luz, arte, ciência... ação! História, Ciências, Saúde - Manguinhos, Rio de Janeiro, v. 12, p. 401-18, 2005. Suplemento.

LUPETTI, K. et al. Magia x ciência: teatro para divulgação científica e ensino de química. In: REUNIÃO ANUAL DA SOCIEDADE BRASILEIRA DE QUÍMICA, 30., 2007, Águas de Lindóia. Resumos... Águas de Lindóia: SBQ, 2007a. Disponível em: < http://sec.sbq.org.br/ cdrom/30ra/resumos/T1412-1.pdf>. Acesso em: 04 fev. 2015.

. Ouroboros: entretenimento e informação. In: ENCONTRO DE EXTENSÃO CONHECIMENTO E DIVERSIDADE CULTURAL, 6., 2007, São Carlos. Caderno de resumos... São Carlos: UFSCar, 2007b.

MASSARANI, L. A divulgação científica, o marketing científico e o papel do divulgador. In: SOUZA, C. M. (Org.). Comunicação ciência e sociedade: diálogos de fronteira. Taubaté: Cabral Editora: Livraria Universitária, 2004. p. 81-94.

MASSARANI, L.; ALMEIDA, C. Arte e ciência no palco. História, Ciência e Saúde Manguinhos, Rio de Janeiro, v. 13, p. 233-246, out. 2006. Suplemento.

MATEUS, A. L. et al. Frankenstein: ensinando ciência através da arte. In: SIMPÓSIO NACIONAL DO ENSINO DE FÍSICA, 16., 2005, Rio de Janeiro. Resumos... Disponível em: <http://www.sbf1.sbfisica.org.br/eventos/snef/xvi/cd/resumos/T0351-1.pdf>. Acesso em: 12 out. 2013.

MATOS, C. (Org.). Ciência e arte: imaginário e descoberta. São Paulo: Terceira Margem, 2003.

MONTENEGRO, B. et al. O papel do teatro na divulgação científica: a experiência da seara da ciência. Ciência \& Cultura, São Paulo, v. 57, n. 4, p. 31-32, 2005. Disponível em: <http://cienciaecultura.bvs.br/pdf/cic/v57n4/a18v57n4.pdf>. Acesso em: 04 fev. 2015.

MOREIRA, L. M. Oxigênio: uma abordagem filosófica visando discussões acerca da educação em ciências - parte 1: poder e ambição. Ciência $\boldsymbol{\&}$ Educação, Bauru, v. 18, n.4, p. 803-818, 2012. Disponível em: <http://dx.doi.org/10.1590/S1516-73132012000400005>. Acesso em: 04 fev. 2015.

O teatro em museus e centros de ciências: uma leitura na perspectiva da alfabetização científica. 2013. 173 f. Tese (Doutorado em Educação) - Faculdade de Educação, Universidade de São Paulo, São Paulo, 2013.

PAVIS, P. Dicionário de teatro. São Paulo: Perspectiva, 2008.

PELLA, M. O.; O'HEARN, G. T.; GALE, C. W. Referents to scientific literacy. Journal of Research in Science Teaching, New York, v. 4, n. 3, p. 199-208, 1966. 
SARAIVA, C. C. Teatro científico e ensino da química. 2007. 170 f. Dissertação (Mestrado em Química para o Ensino) - Faculdade de Ciências, Universidade do Porto, Porto, 2007. Disponível em: <http://nautilus.fis.uc.pt/cec/teses/claudiasaraiva/docs/ tesecompleta.pdf $>$. Acesso em: 04 fev. 2015.

SASSERON, L. H.; CARVALHO, A. M. P. Alfabetização científica: uma revisão bibliográfica. Investigações em Ensino de Ciências, Porto Alegre, v. 16, n. 1, p. 59-77, 2011.

SILVEIRA, A. F.; SILVA, A. P. B.; RIBEIRO FILHO, A. A divulgação da ciência através do teatro: um estudo em Copenhague de Michael Frayn. In: ENCONTRO NACIONAL DE PESQUISA EM EDUCAÇÃO EM CIÊNCIAS, 7, 2009, Florianópolis. Resumos... Disponível em: < posgrad.fae.ufmg.br/posgrad/viienpec/pdfs/359.pdf>. Acesso em: 04 fev. 2015.

SOARES, M. S. M. A Casa da Ciência da UFRJ como espaço de educação nãoformal. 2003. 43 f. Trabalho de Conclusão de Curso (Normal Superior) - Instituto Superior de Educação, Rio de Janeiro, 2003. Disponível em: < http://www.casadaciencia.ufrj.br/ Publicacoes/Dissertacoes/Monografia_Socorro.PDF>. Acesso em: 04 fev. 2015.

STEINGWEG, R. O modelo das peças didáticas: fontes, discussão, experiências. [S.l.: s.n.], 1991.Tradução de Ingrid D. Koudela. Apostila não publicada. 